\title{
Resistência mecânica de compósitos cimentícios leves utilizando resíduos industriais e fibras de sisal ${ }^{1}$
}

\author{
Nivaldo T. de Arruda Filho' ${ }^{2}$, Carolina P. Dantas ${ }^{2}$, Antonio F. Leal ${ }^{2}$, \\ Normando P. Barbosa ${ }^{3}$, Cibelle G. Silva ${ }^{2}$ \& Mavinieux V. Alexandre ${ }^{2}$
}

\begin{abstract}
RESUMO
A valorização de materiais alternativos incorporados com resíduos como opção ao convencional deve possibilitar a geração de um produto com qualidade, estética, produtividade e com potencial de reduzir impactos da poluição ambiental. Este trabalho foi realizado com o objetivo de desenvolver elementos construtivos para forro e divisórias, a partir de matrizes cimentícias com incorporação de resíduos industriais (resíduo cerâmico, etil vinil acetato - EVA) e fibras de sisal. Desenvolveram-se técnicas de moldagem em matrizes cimentícias autoadensáveis e se avaliou a resistência mecânica dos novos compósitos. Uma placa com resíduos de EVA foi produzida e, através de trabalhos de reologia, encontrouse a pasta matriz de revestimento desta placa, com teor adequado de adições pozolânicas e aditivo superplastificante. Avaliaram-se as resistências mecânicas das placas, da pasta matriz de revestimento encontrada, com e sem adição de fibras, e do novo compósito formado pela união desses dois elementos. Utilizou-se a técnica de alinhamento de fibras com o intuito de incrementar resistência ao novo compósito leve. A adição da matriz com fibras alinhadas melhorou a resistência a flexão do novo compósito.
\end{abstract}

Palavras-chave: elementos construtivos, flexão, reologia, fibras de sisal e resíduos industriais

\section{Mechanical resistence of lightweight cement composites utilizing industrial residues and fibers of sisal}

\begin{abstract}
The appreciation of alternative materials incorporated in waste as an option to conventional material should enable to generate a product with quality, aesthetics, productivity and reduce the potential impacts of environmental pollution. This study aims to develop constructive elements for ceilings and walls from cementitious matrix incorporating industrial waste (ceramic waste, ethyl vinyl acetate - EVA) and sisal fibers. Moulding techniques to produce self-compacting cementitious matrices were developed and the strength of the new composites were evaluated. A plate with EVA waste was produced and through rheology studies, a matrix plaster for coating of plate surface was found, with appropriate content of pozzolanic and superplasticizer additions. The mechanical resistance of the plates, the pulp coating matrix, with and without added fiber and the new composite formed by the union of these two elements was assessed. The technique of fiber alignment with the aim of increasing resistance of the new lightweight composite was used. The addition of the matrix with aligned fibers improved the flexural strength of the new composite.
\end{abstract}

Key words: construction elements, bending, rheology, sisal fibers and industrial waste

\footnotetext{
Parte da dissertação de mestrado do primeiro autor

2 UAEA/UFCG. Av. Aprígio Veloso, 882, Bodocongó, CEP 58109-970, Campina Grande, PB. Fone: (83) 2101-1490, Fax: (83) 2101-1490. E-mail: nivaldo.agro@yahoo.com.br; carolinapdantas@yahoo.com.br; leal@deag.ufcg.edu.br; cibelleguimaraes@yahoo.com.br; mavipaisagista@gmail.com

LABEME/UFPB. CEP 58051-900, João Pessoa, PB. Fone: (83) 3216-7910, Fax: (83) 3216-7179. E-mail: nperazzob@yahoo.com.br
} 


\section{INTRODUÇÃO}

Com o crescimento populacional e o aumento do número de indústrias, a geração de resíduos também cresce. Referidos resíduos devem ser tratados de forma correta, o que muitas vezes não é feito, trazendo consequências nocivas ao meio ambiente (Calderoni, 2003).

Dentre as várias formas de processamento e disposição final do lixo, a reciclagem dos resíduos recuperáveis tem sido defendida por entidades ambientalistas e vem obtendo cada vez mais aceitação, em todo o mundo. O reúso ou recuperação desses resíduos além de ajudar nas questões sanitárias e na preservação das reservas naturais de matérias-primas, elimina custos com armazenamento, proporcionando economia para as empresas e para o estado.

A construção civil tem grande potencial para absorver materiais reciclados das indústrias. Isto se justifica pela necessidade de reduzir os custos das obras, pela abundante variedade de matéria-prima e pelo grande número de materiais diferenciáveis aplicados na construção. Então, o que antes era problema pode tornar-se solução: por exemplo, o resíduo de um setor servindo como matéria-prima apta a ser aplicada em outros setores (John et al., 2005).

Sabe-se que um plano de ação para o desenvolvimento sustentável passa pela compreensão e criação de novas oportunidades de mercado através de processos inovadores que garantam uma eficiência maior de recursos/energia e redução dos custos - o que significa a procura de novas utilizações para os subprodutos das indústrias e para os desperdícios da produção (WBCSD, 2009).

Na engenharia civil os compósitos mais empregados são aqueles à base de cimento utilizados sob a forma de concreto com fibras, de argamassa armada e de fibrocimento. Apesar de conhecido há muito tempo, o concreto com fibra representa apenas uma pequena porcentagem do concreto produzido no mundo. A argamassa armada e o fibrocimento ainda são produzidos, essencialmente com fibras de aço e asbesto, respectivamente, apesar da imensa disponibilidade de outras fibras para reforço. Essas limitações ocorreram tendo em vista que só nos últimos 25 anos os princípios relativos à utilização de fibras como reforço de matrizes frágeis (pasta de cimento, argamassa, concreto) começaram a ser compreendido. Com a adição de fibras, a fissuração da matriz frágil é reduzida de vez que as fissuras são interligadas pelas fibras e, como resultado, dá-se um aumento na tenacidade e na resistência à tração e ao impacto. A forma como essas propriedades vão ser modificadas vai depender do tipo de matriz, das propriedades físicas e geométricas das fibras e da interação entre a fibra e a matriz.

Nos últimos anos tem crescido, em todo o mundo, o interesse sobre o potencial de aplicação das fibras vegetais, como o sisal, como possível substituto da fibra de asbesto devido à sua disponibilidade, baixo custo, biodegradação e baixo consumo energético de produção quando comparado com as fibras manufaturadas (Mohr et al., 2006; Roma et al., 2008; Toledo Filho et al., 2009).

A potencialização do uso da fibra de sisal é estratégica para o desenvolvimento do Brasil, visto que é uma das poucas plantas capazes de tornar produtivo o semiárido nordestino. Durante o processo de extração e beneficiamento do sisal no campo, parte do material é composto de fibra curta que, atualmente, tem baixo valor comercial mas apresenta um grande potencial como reforço em produtos de fibrocimento. A utilização de resíduo cerâmico, metacaulinita e de fibras vegetais na produção de fibrocimento, resulta em um material ecologicamente mais eficiente que os tradicionais. O hidróxido de cálcio representa cerca de $20 \%$ dos compostos hidratados do cimento e não contribui para a resistência final do material endurecido. Em presença de argila calcinada se formam, durante a hidratação do cimento, silicatos de cálcio hidratados que podem melhorar a resistência das argamassas e concretos no estado endurecido (Farias Filho et al., 2000; Oliveira \& Barbosa, 2006).

Muitos estudos têm sido desenvolvidos sobre o comportamento das fibras de alto módulo, notadamente de aço havendo, na literatura, vários modelos que descrevem apropriadamente a resposta desses compósitos a deformações ou tensões solicitantes. Para fibras de sisal e coco, esses estudos se concentram no reforço de matrizes dúcteis, sendo ainda reduzida a quantidade de estudos aprofundados sobre o comportamento mecânico dos materiais compósitos à base de cimento, reforçados com essas fibras.

Tendo em vista a necessidade de se reincorporar os resíduos gerados pela indústria de tijolos cerâmicos assim os produzidos pela indústria de calçados e também valorizar a produção de sisal da região, procurou-se desenvolver, neste trabalho, elementos construtivos leves a partir de matrizes cimentícias com incorporação de resíduos industriais (resíduos de tijolos cerâmicos e EVA) e fibras de sisal. Avaliaram-se as adições pozolânicas para formação da matriz cimentícia autoadensável e a resistência mecânica dos compósitos.

\section{MATERIAL E MÉTODOS}

Os resíduos de EVA (etil vinil acetato) foram coletados em uma indústria de calçados na cidade de Campina Grande, PB, e triturados em um moinho de facas rotativas. Obtiveram-se os agregados leves através de peneiras de diferentes aberturas, colocadas na saída do moinho e aparados em sua gaveta frontal. Foram realizados os seguintes ensaios de caracterização física: massa unitária no estado solto; absorção de água e composição granulométrica.

Para elaboração das placas com resíduo de EVA, utilizou-se cimento Portland tipo CPII-F-32, adquirido e acondicionado em sacos de papel do tipo "Kraft" de $50 \mathrm{~kg}$.

As placas de EVA foram produzidas no traço 1:6 (cimento: agregado EVA) em fator água/cimento fixado em 0,55. Utilizaramse uma prensa hidráulica de 30 toneladas e moldes confeccionados com chapas de aço. A tensão de prensagem utilizada foi fixa e igual a 1,65 MPa.

Para a pasta matriz de revestimento, utilizou-se cimento Portland CP II-F-32, de acordo com a norma NBR 11578 (ABNT, 1991d), cuja densidade adotada foi de $3150 \mathrm{~kg} \mathrm{~m}^{-3}$. A relação a/ c, para determinação da pasta matriz de revestimento, também foi determinada de conformidade com a norma NBR NM 43 (ABNT, 2002), cujo valor foi de 0,4 . 
As adições pozolânicas utilizadas foram de tijolo moído proveniente de resíduos da construção civil e a metacaulinita do Brasil, adquiridos através da Universidade Federal da Paraíba, Campus I, João Pessoa, PB.

Foram realizadas as caracterizações físicas dos resíduos que incluem massa e área específica real e análise granulométrica, foram realizadas pelo Método Laser. A caracterização mineralógica incluiu análise para demonstração dos componentes químicos, análise termogravimétrica (TGA), difração dos Raios - X (DRX) e perda de massa. A atividade pozolânica da metacaulinita e do tijolo moído com o cimento Portland foi definida seguindo-se as especificações da NBR 5752/77 (ABNT, 1992), que determinam o índice da atividade pozolânica com o cimento Portland. Utilizou-se um aditivo superplastificante do tipo Mset. O Mset Superplastificante foi adicionado junto com a água de amassamento da própria rede local de abastecimento urbano, variando o teor de $0,3 \mathrm{em} 0,3 \%$ especificamente de 0,3 a $4,5 \%$ do peso do cimento no traço, preferencialmente no final da dosagem de água.

As fibras utilizadas foram adquiridas na Cooperativa do Sisal, na cidade de Pocinhos, PB, separadas e cortadas com 1 cm de comprimento, após testes de avaliação com fibras de várias dimensões $(1 ; 1,5 ; 2,0$ e $2,5 \mathrm{~cm})$ em que as de $1 \mathrm{~cm}$ obtiveram melhores resultados, em termos de trabalhabilidade e resistência na composição das placas. Foram testadas, também, adições de 1,0;1,5 e 2,0\% de peso em fibras de sisal em relaçãoà matriz cimentícia.

O método utilizado para o estudo de comportamento de fluxo das pastas sem fibra foi o do cone de Marsh.

O ensaio no cone de Marsh tem sido usado previamente para avaliar a fluidez e a dosagem ótima de superplastificante nas pastas e argamassas. O procedimento é similar ao do ASTM C 939 (ASTM, 2005), usado para teste de fluidez de graute.

Os aparatos utilizados no ensaio são: o cone de Marsh, um becker graduado de $1000 \mathrm{~mL}$, uma proveta graduada de 500 $\mathrm{mL}$, um cronômetro e os recipientes para acomodar os componentes da mistura, antes do ensaio.

Nos ensaios da pasta matriz deste trabalho se utilizaram: $\mathrm{d}=8 \mathrm{~mm}, \mathrm{~V}=1000 \mathrm{~mL}, \mathrm{v}=500 \mathrm{~mL}$, os mesmos parâmetros empregados por Gomes et al. (2002).

Por meio de alguns ensaios se obteve, para cada pasta, uma curva de tempo de fluxo cuja variável é o percentual de superplastificante sólido. Esta curva é usada para determinação da dosagem ótima do superplastificante.

Para se determinar a melhor mistura visando à elaboração da pasta matriz de revestimento autoadensável, foram estudados diversos pontos como substituição pozolânica na matriz cimentícia, variando as dosagens de tijolo moído e de metacaulinita, incorporados à matriz cimentícia. Os dados obtidos demonstraram a dosagem ótima de superplastificante para a produção da matriz autoadensável, tal como teores ideais de adição mineral para formação da nova matriz.

Tomou-se como base para as substituições pozolânicas, pesquisa desenvolvida por Toledo Filho et al. (2003), que trabalharam com matriz não autoadensável, com substituição pozolânica de $50 \%$ (Matriz $=50 \%$ cimento x $20 \%$ metacaulinita x 30\% tijolo moído).
Após estudo de fluidez e trabalhabilidade do material e determinação do teor ótimo de superplastificante, determinaram-se novos pontos de substituição pozolânica para ensaios de resistência a compressão simples das misturas autoadensáveis. Trabalhou-se com pastas de cimento com substituição variando de 20 a $40 \%$.

Para cada pasta produzida foram moldados seis corpos de prova cilíndricos de dimensões $2,5 \mathrm{~cm}$ de base $\mathrm{x} 5,0 \mathrm{~cm}$ de altura. A moldagem mecânica dos corpos de prova foi iniciada logo após a mistura da pasta, utilizando-se o molde das placas como base e de canos cortados de PVC. Como a pasta era autoadensável, não se necessitou de mesa vibratória para acomodamento das partículas.

Os corpos de prova produzidos foram cobertos com sacos plásticos durante $24 \mathrm{~h}$; este períodoaeles foram desmoldados e colocados à cura em outro recipiente plástico para serem avaliados aos 28 dias.

Foram testadas as resistências à compressão simples das pastas de cimento puro e das pastas com adição pozolânica. Após estudos de reologia adicionou-se, na proporção de 2,1\% do peso do material, o Mset superplastificante com o intuito de melhorar a trabalhabilidade.

O ensaio de resistência à compressão foi realizado de acordo com as recomendações da norma NBR 13279 (ABNT, 2005). Após o estudo de resistência mecânica determinou-se a pasta autoadensável a ser utilizada como pasta matriz de revestimento desta pesquisa (matriz $=80 \%$ de cimento $\times 10 \%$ de metacaulinita x $10 \%$ de tijolo moído $+2,1 \%$ superplastificante), à qual foram adicionadas fibras com volume de $1,5 \%$ e com $1 \mathrm{~cm}$ de comprimento, com diferentes posições dentro da nova mistura. Foi avaliada, também, a distribuição randômica (dispersa) e alinhada das fibras, dentro da pasta matriz de revestimento.

1. Com a mesma mistura se revestiram placas fabricadas com matriz de cimento e resíduo de borracha (EVA), nas dimensões de 18 x 16 × $2 \mathrm{~cm}$;

2. Durante o processo de revestimento das placas tentouse utilizar uma técnica que proporcionasse o alinhamento das fibras de sisal, no intuito de incrementar a resistência à flexão do material;

3. As placas de EVA moldadas foram colocadas por cima de uma camada de cerca de $0,5 \mathrm{~cm}$ da mistura com e sem fibras e desmoldadas após 24 h (Figura 1).
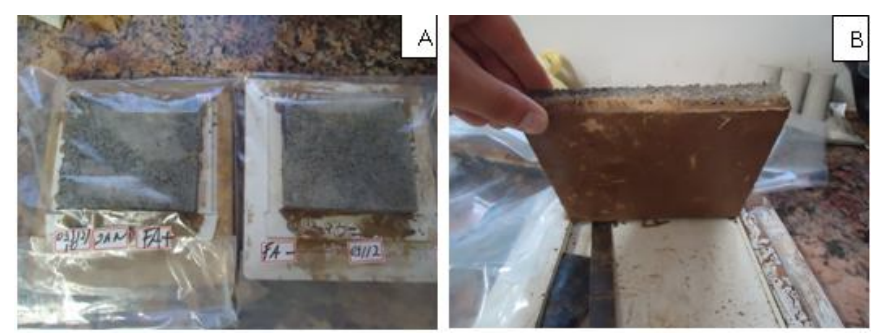

Figura 1. Placas antes (A) e depois (B) do desmolde

A pasta desenvolvida foi utilizada no revestimento das placas de EVA. A técnica de alinhamento das fibras dentro da pasta matriz foi gerada com o propósito de incrementar a resistência mecânica da placa leve de EVA produzida e, consequentemente, obter resultados superiores aos das placas revestidas com a 
matriz e também aos das placas revestidas com a pasta adicionada de fibras distribuídas de forma randômica.

Para se obter tal feito utilizou-se um dispositivo de alimentação com $1 \mathrm{~m}$ de comprimento e se testaram as várias inclinações $\left(15,30,45,60^{\circ}\right)$ em relação ao molde base para formação do novo compósito. As inclinações de $30^{\circ}$ e $45^{\circ}$ foram as que obtiveram resultados mais satisfatórios e foram utilizadas de forma contínua e, no início da experimentação a placa era colocada em um ângulo de $30^{\circ} \mathrm{com}$ a metade do percurso percorrido pela pasta matriz $(0,5 \mathrm{~m})$; já que o comprimento da placa era de $1 \mathrm{~m}$, ela era elevada para um ângulo de $45^{\circ}$, até resultar no alinhamento das fibras adicionada ao revestimento das placas de EVA. As fibras tendiam, consequentemente, a se posicionar paralelamente ao curso da pasta perpendicular ao esforço gerado.

A pasta produzida era lançada na fôrma, seguindo a metodologia de produção, a qual servira de base para receber a placa de EVA, formando assim o novo compósito (pasta matriz + placa EVA). As placas de EVA foram submetidas à umidade visto que, placas com baixo índice de umidade tendiam, após cura, fissurar a pasta de revestimento enquanto, as com alto índice de umidade, tendiam a não fixá-lo. O índice médio de umidade, através de uma pequena molhagem pelo método de borrifação, utilizando-se de um borrifador comum de roupas, foi o ideal para que as placas de EVA se fixassem de forma adequada à pasta matriz.

Após os moldes das placas, as mesmas eram embaladas em sacos plásticos, desmoldadas com 24 h e curadas nos próprios sacos com uma "bucha" de pano, buscando-se o ambiente úmido propício para a cura da matriz (Figura 1).

O ensaio de resistência à flexão foi realizado de acordo com as recomendações da norma NBR 13279 (ABNT, 2005).

Este ensaio analisou as propriedades mecânicas dos corpos de prova prismáticos da pasta matriz de revestimento e do novo compósito (placa de EVA + pasta matriz de revestimento) com e sem fibras, distribuídas de forma randômica e alinhadas dentro da matriz (Figura 2).
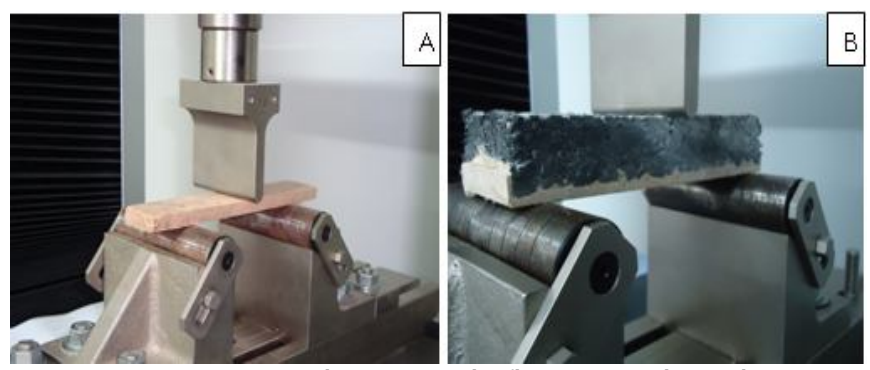

Figura 2. Esquema do ensaio de flexão na placa da pasta matriz de revestimento $(A)$ e no novo compósito $(B)$

\section{RESULTADOS E DISCUSSÃO}

Os agregados de EVA apresentaram baixa massa unitária e alta absorção (Tabela 1). Passados 10 min os agregados absorveram acima de $30 \%$ e após 30 min a absorção foi maior que $60 \%$, confirmando tese de Rios et al. (2009). Em razão da geometria e da moldagem do elemento foi definido um tempo de pré-molhagem de $10 \mathrm{~min}$, para todas as placas.
Tabela 1. Caracterização dos agregados obtidos dos resíduos de etil vinil acetato (EVA)

\begin{tabular}{lcc}
\hline \multirow{2}{*}{ Propriedade } & \multicolumn{2}{c}{ Agregado EVA (mm) } \\
\cline { 2 - 3 } & $\mathbf{4 , 8}$ & $\mathbf{9 , 5}$ \\
Massa unitária em estado solto $\left(\mathrm{kg} \mathrm{m}^{-3}\right)$ & 138,20 & 114,30 \\
Dimensão máxima (mm) & 4,80 & 9,50 \\
Módulo de finura & 4,68 & 6,59 \\
Absorção após 60 min (\%) & 87 & 67 \\
\hline
\end{tabular}

$\mathrm{Na}$ Tabela 2 estão apresentados os resultados das propriedades físicas obtidas na mistura. Cavalcanti Filho (2010) concluiu, estudando vários traços com a mesma mistura, que quanto maior a quantidade de cimento mais elevadas serão as massas e as densidades dos elementos e menor a absorção de água.

Tabela 2. Propriedades físicas das placas

\begin{tabular}{|c|c|c|c|c|c|}
\hline \multirow[t]{2}{*}{ Misturas } & \multirow{2}{*}{$\begin{array}{l}\text { Pressão de } \\
\text { moldagem } \\
(\mathrm{MPa})\end{array}$} & $\begin{array}{c}\text { Massa } \\
\text { saturada }\end{array}$ & $\begin{array}{c}\text { Massa } \\
\text { seca }\end{array}$ & \multirow{2}{*}{$\begin{array}{c}\text { Absorçãa } \\
\text { (\%) }\end{array}$} & \multirow{2}{*}{$\begin{array}{c}\text { Densidade } \\
\left(\mathrm{g} \mathrm{cm}^{-3}\right)\end{array}$} \\
\hline & & \multicolumn{2}{|c|}{ (g) } & & \\
\hline 1:6 & 1,65 & 1452,00 & 1180,40 & 18,71 & 6,6 \\
\hline
\end{tabular}

Os resultados das placas, obtidos aos 28 dias para as resistências a compressão simples e a flexão, mostram que a mistura de 1:6 obteve valores de 2,25 e 0,32 MPa, consecutivamente. Após fissuração da matriz os compósitos leves preparados com agregado de EVA apresentam aumento da capacidade de suporte de carga além de grandes deformações, não existindo a fratura brusca como no caso dos demais compósitos cimentícios sem fibras. A mistura utilizada atende à recomendação do RILEM (1994), em que a resistência a compressão simples deve ser maior ou igual a $0,5 \mathrm{MPa}$ aos 30 dias para concretos leves para fins de isolamento.

No caso específico deste material composto de cimento e resíduo de calçados à base de EVA, foi aferida a resistência à compressão de 2,25 MPa, no traço 1:6 inserindo-lhe, como material propício à aplicação, concreto leve para diversas aplicações (divisórias, forros e isolantes), segundo a norma ASTM (2005).

A massa específica da metacaulinita e do tijolo moído foi de 2,76 e 2,81 $\mathrm{g} \mathrm{cm}^{-3}$ respectivamente, e a área superficial, pelo BET (BET multiponto, com $\mathrm{N}_{2}$ ), é de 0,58 e $0,40 \mathrm{~m}^{2} \mathrm{~g}^{-1}$. O cimento Portland apresenta massa específica de $3,15 \mathrm{~g} \mathrm{~cm}^{-3} \mathrm{e}$ área superficial de $0,30 \mathrm{~m}^{2} \mathrm{~g}^{-1}$.

As normas NBR 5732 (ABNT, 1991a), NBR 5733 (ABNT, 1991b) e NBR 5735 (ABNT< 1991c), prescrevem valores mínimos para a área superficial específica do cimento Portland comum e composto (a partir de $>0,24 \mathrm{~m}^{2} \mathrm{~g}^{-1}$ ), e cimento Portland de alta resistência inicial $\left(>0,30 \mathrm{~m}^{2} \mathrm{~g}^{-1}\right)$.

A distribuição granulométrica das adições pozolânicas, tanto da metacaulinita, como do tijolo moído, está apresentada nas Figuras 3A e 3B, respectivamente, em que na primeira se pode notar a variação de diâmetro do produto entre $0,71 \mu \mathrm{m}$ a $32,46 \mu \mathrm{m}$, com um diâmetro médio de 10,61 $\mu \mathrm{m}$, diferentemente do que demonstra a Figura 3B, na qual o mesmo variou de 2,23 $\mu \mathrm{m}$ (a $10 \%$ ) a 44,82 $\mu \mathrm{m}$ (a $90 \%$ ), com média de $18,78 \mu \mathrm{m}$, comprovando o poder da metacaulinita em absorver água pela finura do material, maior área de exposição aos componentes 


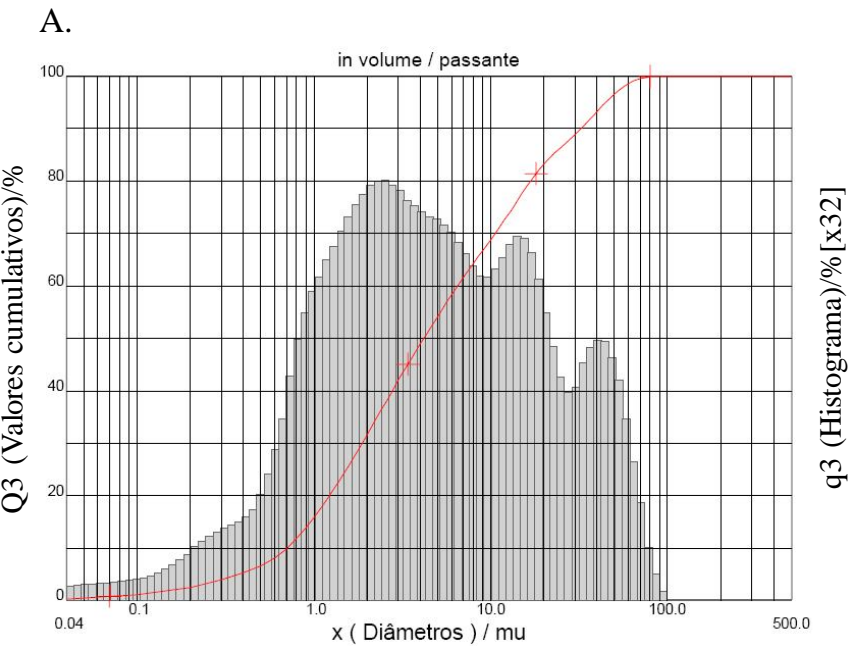

B.

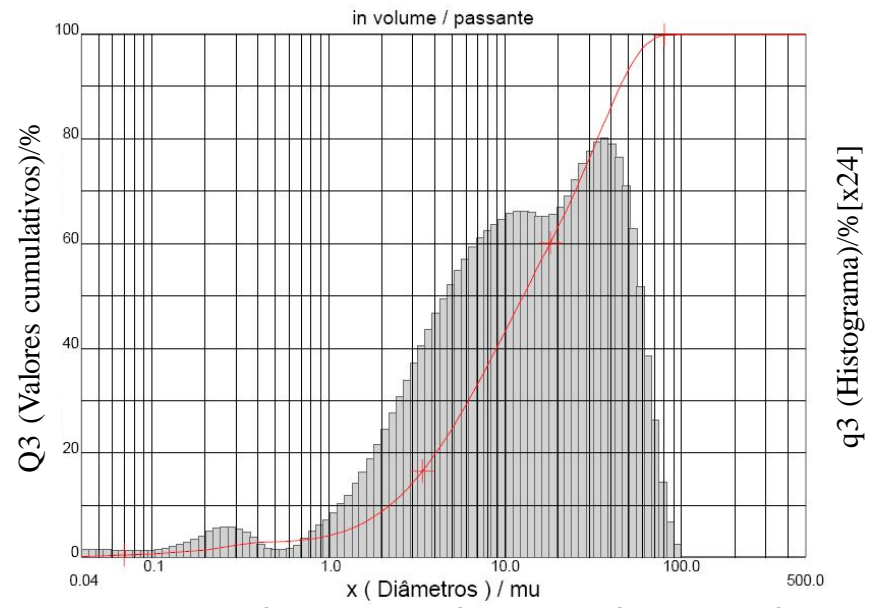

Figura 3. Distribuição granulométrica da metacaulinita (A) e do tijolo moído (B)

da mistura e, em contrapartida, maior teor de aditivo superplastificante a ser incorporado para que a mistura se torne autoadensável.

O método de produção, já que a metacaulinita era um material industrializado, pode ter influenciado na distribuição das partículas e na maior homogeneização da amostra.

Tanto para a metacaulinita como para o tijolo moído, mais de $90 \%$ dos grãos têm diâmetro menor que $40 \mu \mathrm{m}$, o que atende às prescrições da norma ASTM C618 (ASTM, 2005) quanto à finura necessária para uso como pozolana.

A composição química do cimento Portland CP II-F-32, da metacaulinita e do tijolo moído, é apresentada na Tabela 3. A composição química das argilas calcinadas indica que as mesmas possuem teor de $\mathrm{SiO}_{2}+\mathrm{Al}_{2} \mathrm{O}_{3}+\mathrm{Fe}_{2} \mathrm{O}_{3}$ de cerca de $90 \%$, teores de $\mathrm{SiO}_{2}$ e $\mathrm{Al}_{2} \mathrm{O}_{3}$ superiores a, respectivamente, 52 e $27 \%$, e teores de $\mathrm{MgO}$ inferiores a, respectivamente, $3 \%$, atendendo aos limites da norma americana ASTM 618 C (ASTM, 2005) para o uso como adição mineral em misturas com cimento Portland (Souza \& Molin, 2005).

Na composição química dos materiais observou-se uma composição típica de argila sedimentar para cerâmica vermelha, com predominância de $\mathrm{SiO}_{2}, \mathrm{Al}_{2} \mathrm{O}_{3}$ e $\mathrm{Fe}_{2} \mathrm{O}_{3}$. Nota-se alto percentual de $\mathrm{Al}_{2} \mathrm{O}_{3}$, que tende a aumentar a refratariedade da massa argilosa. $\mathrm{O}$ alto teor de $\mathrm{Fe}_{2} \mathrm{O}_{3}$ caracteriza uma massa argilosa que queima tipicamente na cor avermelhada.

O teor de óxido de ferro, de cerca de $6,50 \%$, presente no tijolo moído, fez com que as argamassas produzidas com esse material tivessem cor avermelhada. O teor de óxido de ferro de $3,45 \%$, presente na metacaulinita, não afetou a cor da pasta com cimento Portland. Os teores dos óxidos alcalinos terrosos ( $\mathrm{MgO}$ e CaO) são baixos (Souza \& Molin, 2005).

Para se determinar a atividade pozolânica da metacaulinita e do tijolo moído com o cimento, foram moldados corpos de prova de referência das pastas com até $40 \%$ de adição mineral: M80-10-10; M80-0-20; M80-20-0; M60-20-20; (\% de cimento, tijolo moído e metacaulinita) com $2,1 \%$ de aditivo e fator a/c 0,4. Ensaios de compressão simples realizados indicaram a melhor mistura a ser utilizada como pasta matriz de revestimento da nova placa de EVA produzida (Tabela 4). Por seu elevado poder de escoamento, a pasta de cimento foi avaliada com adição de apenas $0,6 \%$ de aditivo superplastificante, de acordo com o ponto de inflexão da curva de fluidez e trabalhabilidade. A matriz (M-50Ci 20TM 30MC), escolhida por Toledo Filho et al. (2003) e a pasta com cimento puro, serviram como testemunha dos resultados obtidos para a nova pasta autoadensável.

Tabela 4. Resistências mecânicas a compressão simples das pastas

\begin{tabular}{cc}
\hline Mistura & $\begin{array}{c}\text { Compressão } \\
\text { (MPa) }\end{array}$ \\
(Ci; TM e MC; 2,1sp) & 23,6 \\
M60-20-20 & 36,2 \\
M80-10-10 & 34,0 \\
M80-0-20 & 25,2 \\
M80-20-0 & 21,9 \\
*M50-20-30 & 23,2 \\
\hline Cimento; 0,6sp &
\end{tabular}

Através dos resultados apresentados na Tabela 4 nota-se que a melhor mistura está representada por M80-10-10 (\% de $\mathrm{Ci}$; TM e MC) que, por sua vez, mostrou-se superior, em termos de resistência à compressão simples, às outras misturas analisadas.

Todas as misturas estudadas com até $40 \%$ de substituição pozolânica superaram as pastas de cimento puro e a matriz de Toledo Filho et al. (2003) utilizada como testemunha. Este fato deve ter ocorrido pela adição do aditivo superplastificante que, segundo dados do próprio fabricante, a mesma reduz de 10 a

Tabela 3. Análise química das adições minerais utilizadas

\begin{tabular}{|c|c|c|c|c|c|c|c|c|c|c|}
\hline \multirow{2}{*}{ Amostras } & $\mathrm{SiO}_{2}$ & $\mathrm{Al}_{2} \mathrm{O}_{3}$ & $\mathrm{Fe}_{2} \mathrm{O}_{3}$ & $\mathrm{MgO}$ & $\mathrm{K}_{2} \mathrm{O}$ & $\mathrm{TiO}_{2}$ & $\mathrm{SO}_{3}$ & $\mathrm{ZrO}_{2}$ & $\mathrm{CaO}$ & $\mathrm{Cr}_{2} \mathrm{O}_{3}$ \\
\hline & \multicolumn{10}{|c|}{ (\%) } \\
\hline Metacaulim & 52,835 & 40,215 & 3,450 & 1,156 & 1,155 & 1,010 & 0,074 & 0,032 & - & 0,018 \\
\hline Tijolo moído & 59,200 & 27,028 & 6,506 & 1,724 & 3,137 & 1,149 & 0,151 & 0,044 & - & 0,024 \\
\hline Cimento & 17,320 & 6,700 & 1,400 & 11,280 & 0,730 & - & - & - & 53,05 & - \\
\hline
\end{tabular}


$25 \%$ da necessidade de água de amassamento, dependendo do traço utilizado, promovendo aumento das resistências mecânicas e/ou aumento da plasticidade, facilitando a aplicação e reduzindo o consumo de cimento Portland.

A nova pasta matriz escolhida também foi superior, em termos de resistência mecânica à compressão, em 55,53\%, à pasta de cimento, valores bastante superiores ao mínimo estabelecido pela NBR 5752 (ABNT, 1992). As maiores atividades das adições pozolânicas estão diretamente relacionadas à maior fração de $\mathrm{Al}_{2} \mathrm{O}_{3}$ presentes em sua composição química (Tabela 3), uma vez que, segundo Lea (1938), a atividade pozolânica das argilas calcinadas aumenta com o teor $\mathrm{Al}_{2} \mathrm{O}_{3}$.

$\mathrm{O}$ aumento de resistência mecânica está associado à atividade pozolânica, que resulta na formação de novos produtos de hidratação, e à formação de uma estrutura interna menos porosa (Mohr et al., 2006).

O tijolo moído mostrou-se inferior, em termos de incremento de resistência à compressão simples, quando comparado com a metacaulinita, diferente dos ensaios reológicos, em que o tijolo moído apresentou dados que melhoraram a fluidez da pasta. O mesmo deve ter ocorrido pelo fato da metacaulinita ser um material de pequena área específica e, consequentemente, menor o número de vazios formados pelo compósito.

Na Figura 4 pode-se analisar o gráfico da força $(\mathrm{kN}) \mathrm{x}$ deslocamento (mm) da melhor mistura (matriz - 80Ci 10MC 10TM) de material pozolânico-cimento Portland ensaiado na compressão aos 28 dias, encontrada para ser utilizada como pasta matriz de revestimento da placa de EVA produzida.

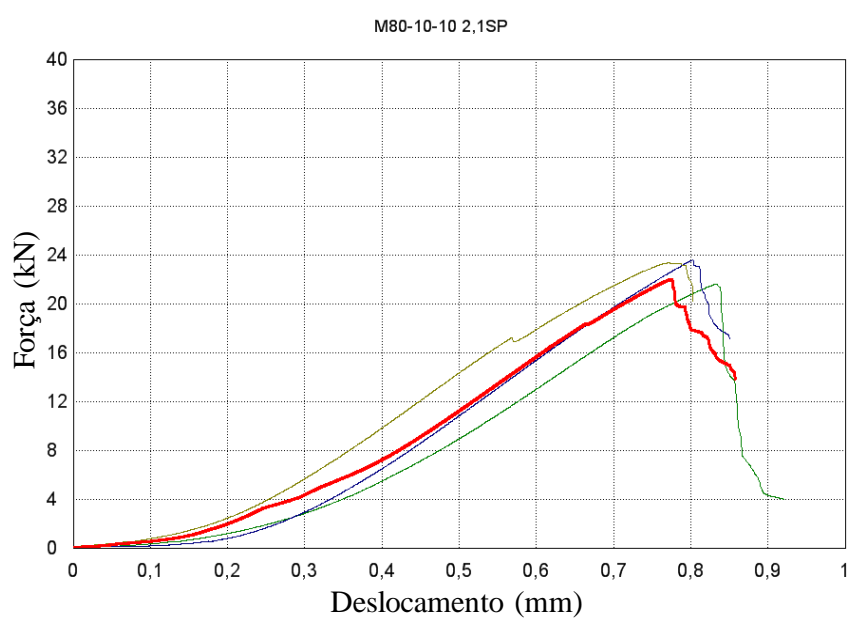

Figura 4. Gráfico da "força X deslocamento" de corpos de prova da melhor mistura (m 8010 10; 2,1sp) ensaiados à compressão

Os resultados mostram que a mistura obteve bom desempenho, em termos de resistência a compressão, que foi de $(21,97 \mathrm{kN})$, muito superior ao encontrado somente com a pasta de cimento sem substituição de cimento por material pozolânico $(14,23 \mathrm{kN})$, confirmado por Farias Filho et al. (2000) que dizem que os resultados de resistência à compressão das misturas com adição pozolânica comparados com os da pasta de referência, indicam que a adição das pozolanas estudadas aumentou, para todas as porcentagens de substituição, sua resistência à compressão. O acréscimo na resistência da pasta de referência variou de 27 a $39 \%$ para o caso em que se utilizou o tijolo queimado moído e de 21 a $72 \%$ para o caso da metacaulinita; nas duas situações a resistência máxima foi atingida para o índice de substituição de $18 \%$, excelente para a formação da pasta matriz que servirá de revestimento para a placa de EVA produzida.

A Figura 5 mostra as curvas típicas, tensão (MPa) $\mathrm{x}$ deformação (\%) para as pastas formadas pela matriz desenvolvida nesta pesquisa com e sem adição de fibras de sisal, distribuídas de forma alinhada e randômica.

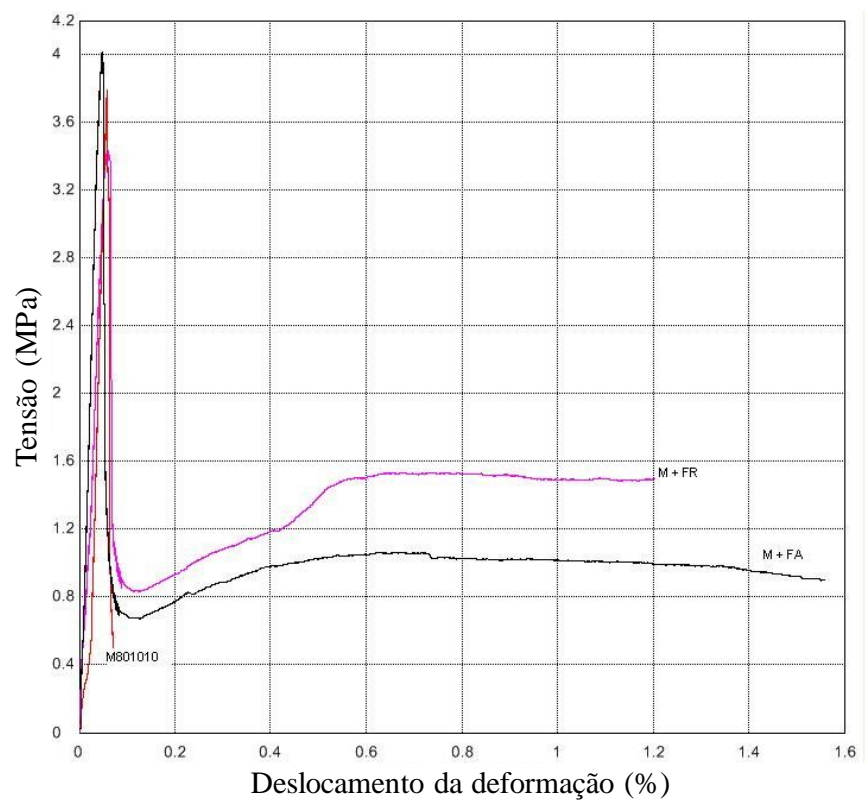

Figura 5. Resultados médios dos ensaios das pastas matriz (m), matriz com fibras randômicas e matriz com fibras alinhadas

Na Figura 5 a curva do ensaio de resistência à flexão da matriz está em marrom claro - m 80:10:10 (cimento, tijolo moído e metacaulinita). Ela é linear até a ruptura, apresentando uma tensão de primeira fissura em torno de 3,8 $\mathrm{MPa}$. O comportamento da pasta com adição de fibras distribuídas de forma randômica possui enorme diferença em relação à matriz, no que se refere ao comportamento pós-fissuração, de vez que a mesma apresenta grande capacidade de absorver energia, com pequena perda de carga de primeira fissura em torno de $3 \%$. A pasta com as fibras distribuídas de forma alinhada, perpendicular ao esforço do ensaio, mostrou-se superior em relação à matriz sem fibras, tanto com incremento de resistência de primeira fissura de 4,01 MPa como em seu comportamento pós-fissuração, quando a mesma absorve as cargas oferecidas e tende a resistir melhor pelo posicionamento das fibras, à deformação.

A pasta matriz com fibras distribuídas de forma alinhada também superou, em termos de carga de primeira fissura, a matriz com fibras dispersas (randômicas) com incremento de $9,76 \%$, devendo ter ocorrido pela posição em que as fibras se encontram em relação à força gerada neste ensaio. A deformação ocorrida na matriz com fibras alinhadas foi semelhante à matriz de fibras randômicas. 
O posicionamento alinhado das fibras e o comportamento em relação à tensão versus deformação mostraram que elas tendem a resistir ao esforço da deformação gerado no corpo de prova.

Analisando a Figura 6A é possível analisar a baixa resistência do material (placa de EVA) em relação ao esforço gerado, em média de $0.3279 \mathrm{MPa}$ tal como o elevado poder de deformação do novo concreto leve no traço de 1:6.

O comportamento da tração na flexão da pasta de cimento é modificado com adição de resíduos de EVA, apresentando o concreto leve (placa EVA) resultante, deformação plástica bastante acentuada após início da fissuração da matriz em todos os casos analisados, passível de ter uma deformação de até $13,7 \%$ (Figura 7).

Os resultados dos ensaios de flexão para o novo compósito formado, placa de EVA revestida com a pasta matriz da melhor mistura com e sem adição de fibras em função das curvas de tensão versus deformação, estão apresentados nas Figuras 6B, 6C e 6D.

Analisando a curva da Figura 6B é possível observar o comportamento do novo compósito revestido com a pasta matriz sem fibras, tornando-se possível caracterizar a média do pico de tensão máxima, que foi de $0,5500 \mathrm{MPa}$, notando-se um incremento de resistência à flexão em relação à placa de EVA sem revestimento da pasta matriz de $28,53 \%$. O comportamento pós-fissuração do material fica representado, basicamente, pela placa de EVA já que, após a fissura da matriz de revestimento, é a mesma que suporta toda a carga oferecida ao novo compósito.

$\mathrm{Na}$ análise da curva da Figura 6C é possível observar o comportamento do novo compósito revestido com a pasta matriz com adição de fibras distribuídas de forma randômica (aleatória). A média do pico de tensão máxima foi de 0,7175 MPa notando-se um incremento de resistência a flexão em relação à placa de EVA revestida pela pasta matriz de $30,45 \%$. Agora, o comportamento pós-fissuração do material já fica representado não só mais pela placa de EVA, mas também pela interação das fibras que compõem o material.

$\mathrm{Na}$ análise da curva média de tensão versus deformação para o compósito revestido com fibras distribuídas de forma alinhada pode-se notar, ainda, um novo incremento de resistência à flexão deste novo material, já que a mesma obteve um valor médio de tensão máxima igual a $0,7479 \mathrm{MPa}$, superando ainda, em $4,23 \%$, os bons resultados obtidos pelo compósito revestido com a matriz de fibras randômicas (Figura 6D).

Em análise às curvas típicas de resistência a flexão, percebese que o compósito que recebeu a pasta matriz de revestimento com adição de fibras distribuídas de forma alinhada dentro da pasta superou, de forma significativa, todos os outros compósitos revestidos ou não, com a pasta matriz escolhida, com e sem adição de fibras com distribuição aleatória. $\mathrm{O}$ fato deve ter ocorrido pela capacidade das fibras distribuídas de forma alinhada, absorver energia.

Analisando-se, ainda, a curva de tensão x deformação do novo compósito com revestimento da pasta com as fibras alinhadas, percebe-se o poder das pontes de ligação que ocorre na matriz de revestimento pós-fissuração, quando perda e aumento de tensão podem ser notados em toda a deformação,
A.

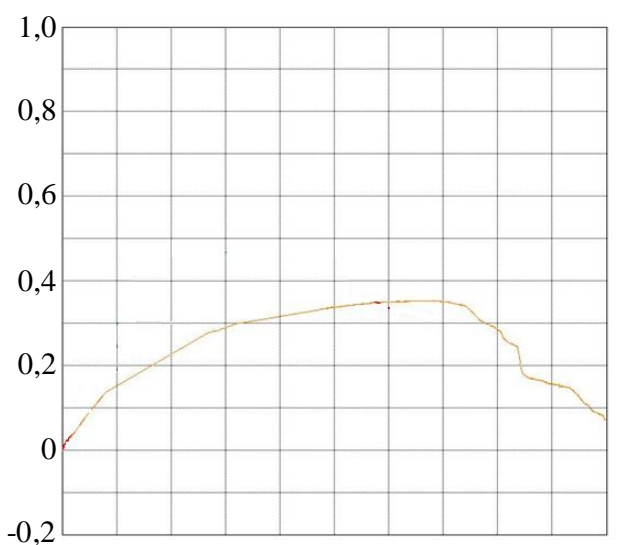

B.

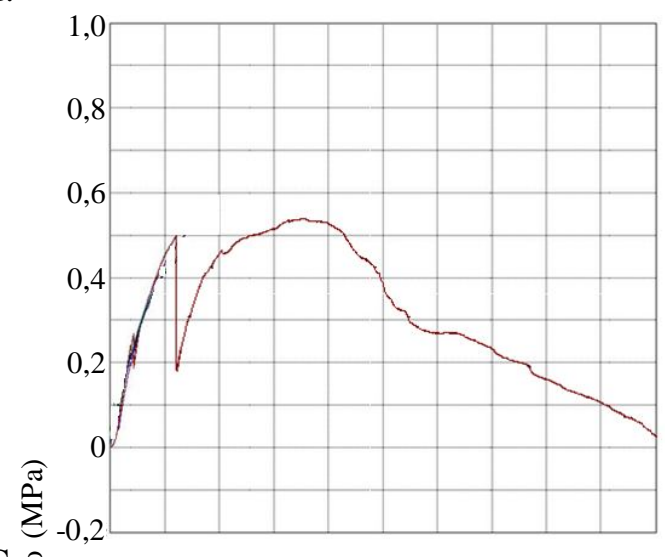

C. 율

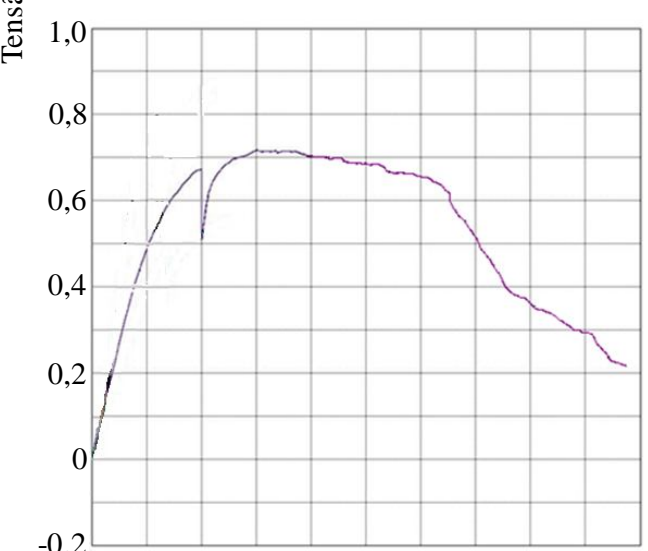

D.

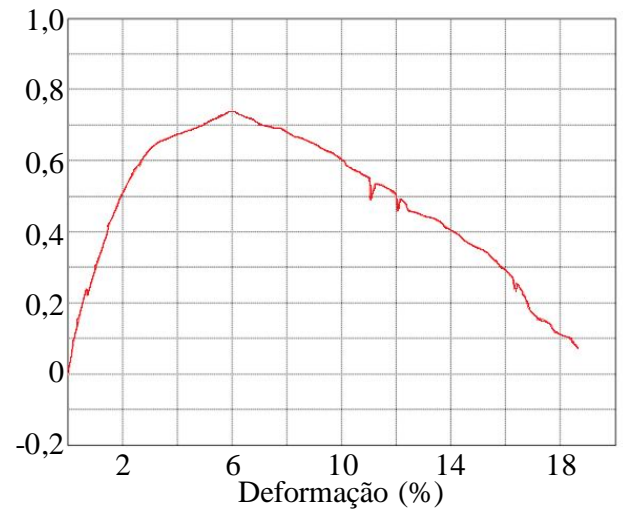

Figura 6. Resultados dos ensaios de flexão das placas de etil vinil acetado (EVA) e do novo compósito (placa EVA + pasta matriz de revestimento) com e sem adição de fibras de sisal 

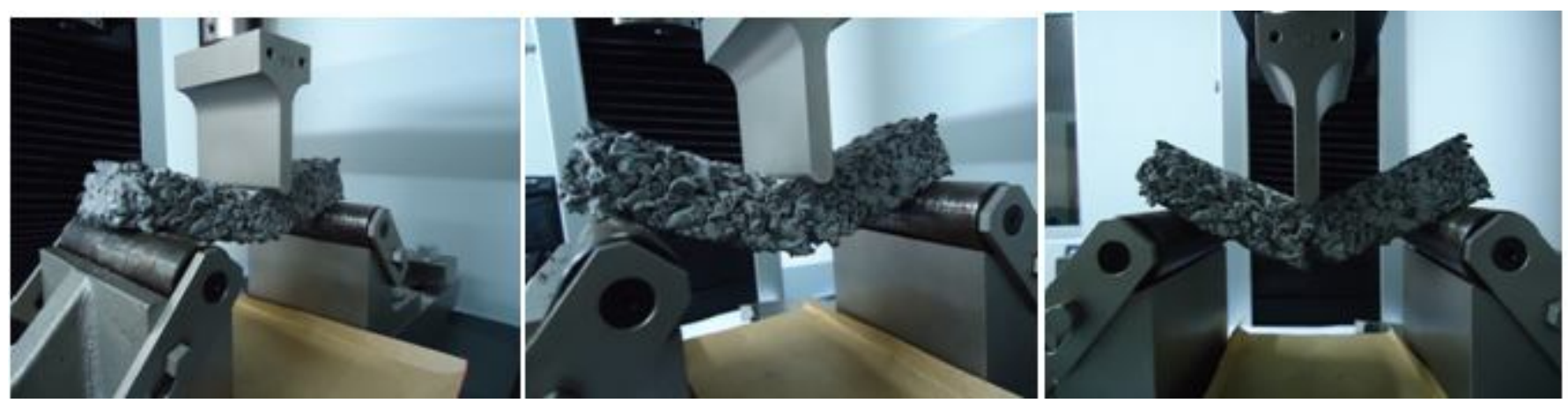

Figura 7. Demonstração do ensaio de resistência à flexão e deformação da placa de etil vinil acetato (EVA) produzida

confirmando o poder de resistir à deformação de cada fibra encontrada no local de fissura do compósito.

A Figura 8 representa o ensaio de tração à flexão e o comportamento das fibras distribuídas de forma alinhada dentro da pasta matriz de revestimento (M 80Ci 10TM 10MC; 2,1sp + fibras alinhadas).

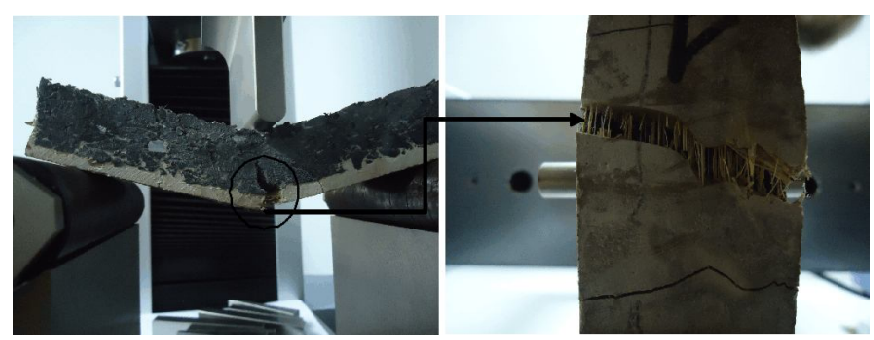

Figura 8. Ensaio de tração à flexão e o comportamento das fibras distribuídas de forma alinhada dentro da pasta matriz de revestimento da placa de etil vinil acetato (EVA)

\section{CONCLUSÕES}

1. Os resultados dos ensaios de resistência a compressão simples indicaram que substituição pozolânica (metaculinita e tijolo moído) aumentaram o comportamento mecânico.

2. O melhor comportamento da pasta matriz de revestimento é observado após 28 dias de cura em ambiente úmido.

3. A incorporação das fibras a pasta de revestimento da placa de etil vinil acetato (EVA), sejam elas distribuídas de forma randômica ou alinhadas dentro da pasta, acrescentaram resistência à flexão ao novo compósito quando comparada com a placa de EVA revestida com a pasta de matriz sem adição de fibras.

4. As fibras distribuídas de forma alinhadas dentro da pasta de revestimento, incrementaram resistência á flexão ao compósito (pasta matriz + placa de EVA) sendo esta, superior ao compósito com a pasta matriz de revestimento com fibras randômicas e sem fibras.

\section{LITERATURA CITADA}

ABNT - Associação Brasileira de Normas Técnicas. NBR 5732: Cimento Portland Comum. Rio de Janeiro: ABNT, 1991a. 5p. ABNT - Associação Brasileira De Normas Técnicas. NBR 5733 - Cimento Portland de alta resistência inicial. Rio de Janeiro: ABNT, 1991b. 5p.
ABNT - Associação Brasileira de Normas Técnicas. NBR 5735. Cimento Portland de alto forno. Rio de Janeiro: ABNT, 1991c. $10 \mathrm{p}$.

ABNT - Associação Brasileira de Normas Técnicas. NBR 11578. Cimento Portland composto. Rio de Janeiro: ABNT, 1991d. 5p.

ABNT - Associação Brasileira de Normas Técnicas. NBR 5752/ 92. Materiais pozolânicos - Determinação de atividade pozolânica com cimento Portland - Índice de atividade pozolânica com cimento. Rio de Janeiro: ABNT, 1992. 3p.

ABNT - Associação Brasileira de Normas Técnicas. NBR NB43. Cimento Portland - Determinação da pasta de consistência normal. Rio de Janeiro: ABNT, 2002. 8p.

ABNT - Associação Brasileira de Normas Técnicas. NBR 13279. Argamassa para assentamento e revestimento de paredes e tetos: Determinação da resistência à tração na flexão e à compressão. Rio de Janeiro: ABNT, 2005. 9p.

ASTM - Cement Standards and Concrete Standards, ASTM C 939, ASTM International, Metals Park, OH, 2005.

Calderoni, S. Os bilhões perdidos no lixo. São Paulo: Humanitas Editora, 2003.345p.

Cavalcanti Filho, A. N. Contribuição ao controle tecnológico de concretos estruturais de cimento Portland em ambientes marítimos. São Paulo: USP. 2010. 334p. Dissertação Mestrado

Farias Filho, J.; Rolim, J. M. S.; Toledo Filho, R. D. Potencialidades da metacaolinita e do tijolo queimado moído como substitutos parciais do cimento Portland. Revista Brasileira de Engenharia Agrícola e Ambiental, v.4, p.437444, 2000.

Gomes, A. M.; Nero, J. M. G.; Appleton, J. A. S. Novo método para a avaliação da trabalhabilidade e consistência das argamassas. In: Simpósio Brasileiro de Tecnologia das Argamassas, I. Goiânia: Anais...Goiânia, p.83-91, 2002.

John, V. M.; Cincotto, M. A.; Sjöström, C.; Agopyan, V.; Oliveira, C. T. A. Durability of slag mortar reinforced with coconut fibre. Cement and Concrete Composites, v.27, p.567-574, 2005.

Lea, F. M. The chemistry of pozzolans. In: Symposium on the Chemistry Of Cement, Proceedings... Stockolm: Ingeniörsveteuskapsakademieu, p.460-490, 1938.

Mohr, B. J.; Nanko, H.; Kurtis, K. E. Aligned kraft pulp fiber sheets for reinforcing mortar. Cement and Concrete Composites, v.28, p.161-172, 2006.

Oliveira, M. P. de; Barbosa, N. P. Potencialidades de um caulim calcinado como material de substituição parcial do cimento Portland em argamassas. Revista Brasileira de Engenharia Agrícola eAmbiental, v.10, p.490-496, 2006. 
RILEM - Research Laboratories for Materials and Construction. International Union of Testing and Research Laboratories for Materials and Construction. RILEM technical recommendations for the testing and use of construction materials. London: E \& FN Spon, 1994.

Rios, F. R. A.; Silva, V. R. da; Soares, E. A.; Leal, A. F.; Nascimento, J. W. B. do. Incorporação do SBR na confecção de compósitos de matriz cimentícia. Revista de Educação Agrícola Superior, v.24, p.13-19, 2009.

Roma Júnior, L. C.; Martello, L. S.; Savastano Júnior, H. Evaluation of mechanical, physical and thermal performance of cement-based tiles reinforced with vegetable fibers. Construction and Building Materials, v.22, p.668674, 2008.
Souza, P. S. L.; Molin, D. C. C. dal. Estudo da viabilidade do uso de argilas calcinadas, como metacaulim de alta reatividade (MCAR). Revista Engenharia Civil, n.15, p.45-54, 2002.

Toledo Filho, R. D.; Ghavami, K.; England, G. L.; Scrinever, K. Development of vegetable fibre-mortar composites of improved durability. Cement and Concrete Composites, v.25, p.185-196, 2003.

Toledo Filho, R. D.; Silva, F. A.; Fairbairn, E. M. R.; Melo Filho, J. A. Durability of compression molded sisal fiber reinforced mortar laminates. Construction and Building Materials, v.23, p.2409-2420, 2009.

WBCSD - World Business Council for Sustainable Development - The cement sustainability initiative: Cement Industry and $\mathrm{CO}_{2}$ Performance - Getting the Numbers Right, 2009. 